\title{
Max-Phases Investigated by Soft X-Ray Emission Spectroscopy
}

\author{
Martin Magnuson \\ Linköping University Post Print
}

N.B.: When citing this work, cite the original article.

Original Publication:

Martin Magnuson, Max-Phases Investigated by Soft X-Ray Emission Spectroscopy, 2006, Mechanical Properties and Performance of Engineering Ceramics II: Ceramic Engineering and Science Proceedings, Volume 7, Issue 2, 325-329.

http://dx.doi.org/10.1002/9780470291313.ch31

Copyright: (C) 2006 John Wiley \& Sons, Inc. All Rights Reserved. http://onlinelibrary.wiley.com/

Postprint available at: Linköping University Electronic Press

http://urn.kb.se/resolve?urn=urn:nbn:se:liu:diva-55065 
Mechanical Properties and Performance of Engineering Ceramics II: Ceramic Engineering and Science Proceedings, Volume 7, Issue 2 / [ed] Rajan Tandon, Andrew Wereszczak, Edgar Lara-Curzio, (2006), 325-329: DOI: 10.1002/9780470291313.ch31

\title{
MAX-PHASES INVESTIGATED BY SOFT X-RAY EMISSION SPECTROSCOPY
}

\author{
Martin Magnuson \\ Department of Physics, Uppsala University, P. O. Box 530, S-75121 Uppsala, Sweden
}

\begin{abstract}
The electronic structures of the MAX-phases $\mathrm{Ti}_{3} \mathrm{AlC}_{2}, \mathrm{Ti}_{3} \mathrm{SiC}_{2}$ and $\mathrm{Ti}_{3} \mathrm{GeC}_{2}$ were investigated by soft X-ray emission spectroscopy. These nanolaminated carbide compounds represent a class of layered materials with a combination of properties from both metals and ceramics. The bulksensitive soft X-ray emission technique is shown to be particularly useful for detecting detailed electronic structure information about internal monolayers and interfaces. A weak covalent Ti$\mathrm{Al}$ bond is manifested by a pronounced shoulder in the Ti $L$-emission of $\mathrm{Ti}_{3} \mathrm{AlC}_{2}$. When $\mathrm{Al}$ is replaced by $\mathrm{Si}$ or $\mathrm{Ge}$, the shoulder disappears. Furthermore, the spectral shapes of $\mathrm{Al}, \mathrm{Si}$ and $\mathrm{Ge}$ in the MAX-phases are strongly modified in comparison to the corresponding pure elements. By varying the constituting elements, a change of the electron population is achieved causing a change of covalent bonding between the laminated layers, which enables control of the macroscopic properties of the material.
\end{abstract}

\section{INTRODUCTION}

In the last few years, the interest in ternary carbides and nitrides, so-called $M_{n+1} A X_{n}$-phases has grown significantly both from a scientific and a technological point of view [1]. Generally, there are three different kinds of crystal structures of these materials, often denoted 211, 312 and 413, corresponding to $\mathrm{n}=1,2$ and 3 . The letter $\mathrm{M}$ denotes an early transition metal, $\mathrm{A}$ is an element in the groups IIIA and IVA and $\mathrm{X}$ is either carbon or nitrogen. The MAX-phases exhibit a unique combination of metallic and ceramic properties, including high strength and stiffness at high temperature, resistance to oxidation and thermal shock, and display high electrical and thermal conductivity [1]. The unique macroscopic properties of the MAX-phases are related to the underlying nanolaminated crystal structure, the electronic structure and the chemical bonding of the individual atomic layers. For the 312-crystal structure, there are three different carbides, $\mathrm{Ti}_{3} \mathrm{AlC}_{2}, \mathrm{Ti}_{3} \mathrm{SiC}_{2}$ and $\mathrm{Ti}_{3} \mathrm{GeC}_{2}$. Sintered bulk MAX-compounds are useful in many technological high-temperature applications such as heating elements in ovens. In other applications where e.g., low-friction properties are useful, high-quality thin film coatings of MAX-phases are utilized.

In this paper, soft X-ray emission (SXE) spectroscopy was applied to probe the partial electronic structures of $\mathrm{Ti}_{3} \mathrm{AlC}_{2}, \mathrm{Ti}_{3} \mathrm{SiC}_{2}$ and $\mathrm{Ti}_{3} \mathrm{GeC}_{2}$. The photon-in-photon-out $\mathrm{SXE}$ spectroscopic technique is element selective and more bulk sensitive than electron-based techniques such as $\mathrm{X}$ ray absorption and X-ray photoemission spectroscopy [2-4]. This makes it possible to obtain information about the buried internal monolayers and interfaces in the compounds. Each element in the MAX-phase compounds was probed separately and the partial electronic structures of the valence bands were projected through the dipole transition selection rules. 


\section{EXPERIMENT}

The SXE measurements were performed at the undulator beamline I511-3 at MAX II (MAX-lab National Laboratory, Lund University, Sweden), which includes a 49-pole undulator and a modified SX-700 plane grating monochromator [5]. The SXE spectra were recorded with a high-resolution Rowland-mount grazing-incidence grating spectrometer [6] with a twodimensional detector. The Ti $L$ and $\mathrm{C} K \mathrm{X}$-ray emission spectra were recorded using a spherical grating with 1200 lines $/ \mathrm{mm}$ of $5 \mathrm{~m}$ radius in the first order of diffraction. The $\mathrm{Al} L, \mathrm{Si} L$ and $\mathrm{Ge}$ $M$ spectra were recorded using a grating with 300 lines $/ \mathrm{mm}, 3 \mathrm{~m}$ radius in the first order of diffraction. During the SXE measurements at the Ti $2 p, \mathrm{C} 1 s, \mathrm{Al} 2 p$, Si $2 p$ and Ge $3 p$ edges, the resolutions of the beamline monochromator were 1.6, 1.0,0.3, 0.2, and $0.4 \mathrm{eV}$, respectively. The SXE spectra were recorded with spectrometer resolutions $0.7,0.2,0.2,0.2,0.2 \mathrm{eV}$, respectively. The measurements were performed with a base pressure lower than $5 \times 10^{-9}$ Torr. In order to minimize self-absorption effects [7], the angle of incidence was 30 degrees from the surface plane during the emission measurements. The X-ray photons were detected parallel to the polarization vector of the incoming beam in order to minimize elastic scattering. The deposition procedure of the epitaxially grown thin film coatings are described elsewhere [8].

\section{RESULTS AND DISCUSSION}

Figure 1 shows a set of soft X-ray emission spectra excited nonresonantly above the Ti $L_{2,3}, \mathrm{C} K$, Al $L_{2,3}$, Si $L_{2,3}$ and $\mathrm{Ge} M_{2,3}$ edges for $\mathrm{Ti}_{3} \mathrm{AlC}_{2}, \mathrm{Ti}_{3} \mathrm{SiC}_{2}$ and $\mathrm{Ti}_{3} \mathrm{GeC}_{2}$. The excitation energies were $477 \mathrm{eV}, 310 \mathrm{eV}, 120 \mathrm{eV}, 120 \mathrm{eV}$ and $165 \mathrm{eV}$, respectively. For comparison, the spectra are normalized to unity and plotted on a common photon energy scale relative to the Fermi level $\left(\mathrm{E}_{\mathrm{F}}\right)$ using core level XPS binding energies for the same type of compounds available in the literature [3,4]. For Ti 2 $\mathrm{p}_{3 / 2}, \mathrm{C} 1 \mathrm{~s}, \mathrm{Si} 2 \mathrm{p}, \mathrm{Al} 2 \mathrm{p}$, and $\mathrm{Ge} 3 \mathrm{p}_{1 / 2}, 454.7 \mathrm{eV}, 281.83 \mathrm{eV}, 99.52 \mathrm{eV}$ [3], $71.9 \mathrm{eV}$ [4] and $125.5 \mathrm{eV}$ [8] binding energies were used, respectively.

In the Ti $L_{23}$ spectra at the top of Fig. 1, the main $L_{3}$ and $L_{2}$ emission lines dominated by $3 d$ final states are observed at $-2.5 \mathrm{eV}$ and $3.7 \mathrm{eV}$ and the intensity of the $L_{3}$ emission line is about 6 times higher than the $L_{2}$ intensity. The measured peak splitting due to the spin-orbit interaction is thus $6.2 \mathrm{eV}$. Notably, a broad peak structure is also observed at $-10 \mathrm{eV}$ in all three $\mathrm{Ti} L_{2,3}$ spectra. This structure is not observed in Ti $L_{2,3}$ spectra of pure $\mathrm{Ti}$ [9] and can therefore be attributed to hybridization with carbon. The arrow at the top of Fig. 1 indicates the most significant difference between the three systems, namely the pronounced shoulder in the $\mathrm{Ti}_{3} \mathrm{AlC}_{2}$ system. The peak splitting between the shoulder and the main line is $1.5 \mathrm{eV}$. The shoulder clearly originates from hybridization with $\mathrm{Al}$ in $\mathrm{Ti}_{3} \mathrm{AlC}_{2}$, an interpretation that is also consistent with bandstructure calculations $[8,10]$.

In the $\mathrm{C} K$ spectra, the main peak is found at $-2.6 \mathrm{eV}$ and there are shoulders on both the lowand high-energy sides of the main peak at $-4.2 \mathrm{eV}$ and $-2 \mathrm{eV}$. The main peak and the shoulder correspond to the occupied C $2 p$ orbitals hybridized with the Ti $3 d$ bonding and antibonding orbitals of the valence bands [8]. Note that the three $\mathrm{C} K$ spectra have very similar spectral shapes. This suggests that the interaction between the $\mathrm{C}$ and A atoms is very small.

The $\mathrm{Al} L_{2,3}$ spectrum of $\mathrm{Ti}_{3} \mathrm{AlC}_{2}$, has the main peak at $-3.9 \mathrm{eV}$ and is dominated by $3 s$ final states. Al $3 p$ states dominate close to $\mathrm{E}_{\mathrm{F}}$ but are dipole forbidden at the $2 p$ edges and do not 


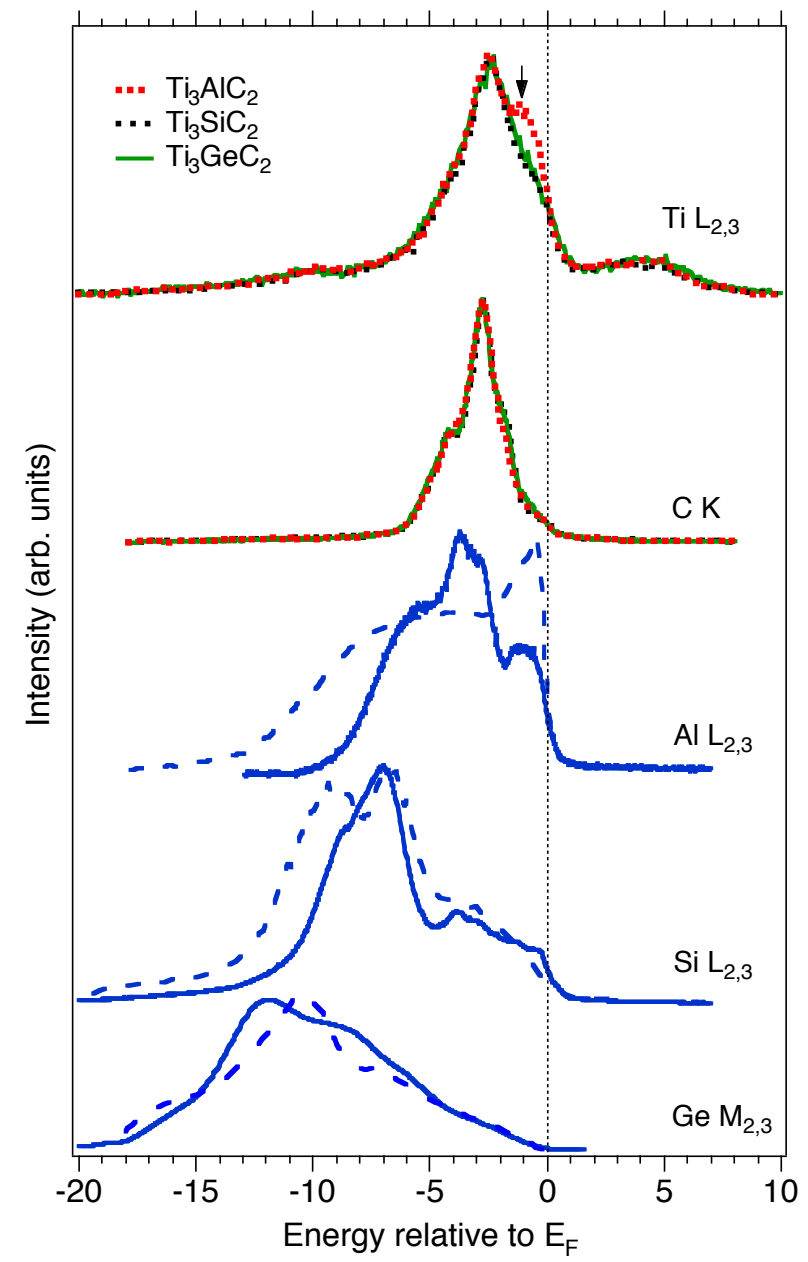

Figure 1: (Color) $\mathrm{Ti} L, \mathrm{C} K, \mathrm{Al} L, \mathrm{Si} L$ and Ge $M$ X-ray emission spectra of the MAX-phases $\mathrm{Ti}_{3} \mathrm{AlC}_{2}, \mathrm{Ti}_{3} \mathrm{SiC}_{2}$ and $\mathrm{Ti}_{3} \mathrm{GeC}_{2}$. The excitations were made nonresonantly at 477 $\mathrm{eV}, 310 \mathrm{eV}, 120 \mathrm{eV}, 120 \mathrm{eV}$ and $165 \mathrm{eV}$, respectively. The spectra were aligned on a common energy scale relative to the Fermi level $\left(\mathrm{E}_{\mathrm{F}}\right)$ by using core-level XPS binding energies [3,4] $(454.7 \mathrm{eV}, 281.83 \mathrm{eV}, 71.9 \mathrm{eV}, 99.52 \mathrm{eV}$, and $125.5 \mathrm{eV}$, respectively). The measured spectral profiles of $\mathrm{Al}, \mathrm{Si}$ and $\mathrm{Ge}$ are compared to spectra of the pure elements from Refs. [11, 13, 15] (dashed lines). The Ge spectrum (bottom) was smoothed with a binomial average of the raw data. contribute to the spectrum. The spectral profile of $\mathrm{Al}$ in $\mathrm{Ti}_{3} \mathrm{AlC}_{2}$ also differ substantially from spectra of pure $\mathrm{Al}$ metal which has a sharp and dominating peak structure close to $\mathrm{E}_{\mathrm{F}}$ [11]. A similar spectral profile as in $\mathrm{Al}$ of $\mathrm{Ti}_{3} \mathrm{AlC}_{2}$ has been observed in the metal aluminides [12].

The $\mathrm{Si} L_{2,3}$ spectrum of $\mathrm{Ti}_{3} \mathrm{SiC}_{2}$, is dominated by a peak structure at $-7 \mathrm{eV}$, at significantly lower energy than in Al. The lower energy of the main structure in $\mathrm{Si}$ is related to the extra valence electron in $\mathrm{Si}$ in comparison to $\mathrm{Al}$. As in the case of $\mathrm{Al}$, the $\mathrm{Si} L_{2,3}$ spectrum is dominated by $3 s$ final states and the $\mathrm{Si}$ $3 p$ states are dipole forbidden. The spectral profile of $\mathrm{Si}$ in $\mathrm{Ti}_{3} \mathrm{SiC}_{2}$ also largely differs from spectra of pure $\mathrm{Si}$, which has a pronounced double structure [13]. The spectral shape of $\mathrm{Si}$ in $\mathrm{Ti}_{3} \mathrm{SiC}_{2}$ is similar to the metal silicides [14].

As shown at the bottom of Fig. 1, the Ge $\mathrm{M}_{2,3}$ emission spectrum of $\mathrm{Ti}_{3} \mathrm{GeC}_{2}$ is dominated by a double structure with peaks at -12 and $-8 \mathrm{eV}$. These peaks are due to the $M_{3}$ and $M_{2}$ emission lines. The measured $M_{2,3}$ emission of the $4 s$ valence band of $\mathrm{Ge}$ in $\mathrm{Ti}_{3} \mathrm{GeC}_{2}$ is about two orders of magnitude weaker than the $\mathrm{Al} L_{2,3}$ emission in $\mathrm{Ti}_{3} \mathrm{AlC}_{2}$ and the Si $L_{2,3}$ emission in $\mathrm{Ti}_{3} \mathrm{SiC}_{2}$ and for comparison of the spectral profiles the raw data of $\mathrm{Ge}$ was smoothed in figure 1. The double structure observed in the

Ge $M_{2,3}$ emission spectrum of $\mathrm{Ti}_{3} \mathrm{GeC}_{2}$ is significantly different from the triple-peak structure in Ge $M_{2,3}$ emission of pure $\mathrm{Ge}$ [15]. As in the case of $\mathrm{Si}$, the spectral shape of $\mathrm{Ge}$ in $\mathrm{Ti}_{3} \mathrm{GeC}_{2}$ is similar to the metal germanides [16].

A comparison between the spectral profiles of measured MAX-phases and electronic structure calculations including core-to-valence dipole transition matrix elements is presented elsewhere [8] yielding a qualitative agreement in the interpretation between experiment and theory. 
Mechanical Properties and Performance of Engineering Ceramics II: Ceramic Engineering and Science Proceedings, Volume 7, Issue 2 / [ed] Rajan Tandon, Andrew Wereszczak, Edgar Lara-Curzio, (2006), 325-329: DOI: 10.1002/9780470291313.ch31

\section{CONCLUSION}

Soft X-ray emission spectra of the MAX-phases $\mathrm{Ti}_{3} \mathrm{AlC}_{2}, \mathrm{Ti}_{3} \mathrm{SiC}_{2}$ and $\mathrm{Ti}_{3} \mathrm{GeC}_{2}$ are presented. The most significant difference between the three compounds is a double structure in the Ti $L_{2,3}$ emission of $\mathrm{Ti}_{3} \mathrm{AlC}_{2}$. This is related to the fact that the Ti-Al bonding displays less covalent character than the Ti-Si and Ti-Ge bonds. The X-ray emission spectral profiles of $\mathrm{Al}$ in $\mathrm{Ti}_{3} \mathrm{AlC}_{2}$, $\mathrm{Si}$ in $\mathrm{Ti}_{3} \mathrm{SiC}_{2}$ and $\mathrm{Ge}$ in $\mathrm{Ti}_{3} \mathrm{GeC}_{2}$ are found to be very different in comparison to the corresponding pure elements. These strongly modified spectral structures are due to significant hybridization with the surrounding $\mathrm{Ti}$ and $\mathrm{C}$. By replacing $\mathrm{Al}$ with the isoelectronic $\mathrm{Si}$ and $\mathrm{Ge}$ elements, the achieved change in the valence electron population and thus the modified chemical bonding implies a change of the macroscopic material properties.

\section{REFERENCES}

[1] M. W. Barsoum; Prog. Solid State Chem. 28, 201 (2000).

[2] N. I. Medvedeva, D. L. Novikov, A. L. Ivanovsky, M. V. Kuznetsov and A. J. Freemena; Phys. Rev. B 58, 16042 (1998).

[3] S. E. Stoltz, H. I. Starnberg and M. W. Barsoum; J. Phys. and Chem. Of Solids; 64, 2321 (2003).

[4] S. Myhra, J. A. A. Crossley and M. W. Barsoum; J. Phys. Chem. Solids; 62, 811 (2001).

[5] R. Denecke, P. Vaterlein, M. Bassler, N. Wassdahl, S. Butorin, A. Nilsson, J.-E. Rubensson, J. Nordgren, N. Mårtensson and R. Nyholm; J. Electron Spectrosc. Relat. Phenom. 101103, 971, (1999).

[6] J. Nordgren and R. Nyholm; Nucl. Instr. Methods A246, 242 (1986); J. Nordgren, G. Bray, S. Cramm, R. Nyholm, J.-E. Rubensson and N. Wassdahl; Rev. Sci. Instrum. 60, 1690 (1989).

[7] S. Eisebitt, T. Böske, J.-E. Rubensson and W. Eberhardt; Phys. Rev. B 47, 14103 (1993).

[8] M. Magnuson, J.-P. Palmquist, M. Mattesini, S. Li, R. Ahuja, O. Eriksson, J. Emmerlich, O. Wilhelmsson, P. Eklund, H. Högberg, L. Hultman and U. Jansson; Phys. Rev. B 72, 245101 (2005).

[9] E. Z. Kurmaev, A. L. Ankudinov, J. J. Rehr, L. D. Finkelstein, P. F. Karimov and A. Moewes; J. Elec. Spec. 148, 1 (2005).

[10] Y. Zhou, Z. Sun, X. Wang and S. Chen; J. Phys. Condens. Matter 13, 10001 (2001).

[11] D. L. Ederer, R. Schaefer, K.-L. Tsang, C. H. Zhang, T. A. Callcott and E. T. Arakawa; Phys. Rev. B 37, 8594 (1988).

[12] K. Ichikawa; J. Phys. Soc. Jpn. 37, 377 (1994).

[13] P. O. Nilsson, J. Kanski, J. V. Thordson, T. G. Andersson, J. Nordgren, J. Guo, and M. Magnuson; Phys. Rev B 52, R8643 (1995).

[14] J. J. Jia, T. A. Callcott, W. L. O’Brien, Q. Y. Dong, J.-E. Rubensson, D. R. Mueller, D. L. Ederer and J. E. Rowe; Phys. Rev. B 43, 4863 (1991).

[15] P. O. Nilsson, S. Mankefors, J. Guo, J. Nordgren, D. Debowska-Nilsson, W. X. Ni, and G. V. Hansson; Phys. Rev. B 64, 115306 (2001).

[16] I. V. Kavich, B. N. Yatsyk, and A. B. Nazarchuk; Phys. Met. Metallorg. 5, 1094 (1985). 